\title{
Pharmacokinetic-pharmacodynamic evaluation of ceftazidime continuous infusion vs intermittent bolus injection in septicaemic melioidosis
}

\author{
B. J. Angus, ${ }^{1,2}$ M. D. Smith, ${ }^{1,2,+}$ Y. Suputtamongkol, ${ }^{1,5}$ H. Mattie, ${ }^{3}$ A. L. Walsh, ${ }^{1,2, \dagger}$ V. Wuthiekanun, \\ W. Chaowagul ${ }^{4} \&$ N. J. White ${ }^{1,2}$ \\ ${ }^{1}$ Faculty of Tropical Medicine, Mahidol University, $420 / 6$ Rajvithi Road, Bangkok 10400, Thailand, ${ }^{2}$ Centre for Tropical Medicine, Nuffield Department \\ of Clinical Medicine, John Radcliffe Hospital, Oxford University, Oxford, United Kingdom, ${ }^{3}$ Department of Infectious Diseases, University Hospital, \\ Leiden, The Netherlands, ${ }^{4}$ Department of Medicine, Sappasitprasong Hospital, Ubon Ratchatani, Thailand and ${ }^{5}$ Department of Medicine, Siriraj Hospital, \\ Bangkok, Thailand
}

\begin{abstract}
Aims Experimental studies have suggested that constant intravenous infusion would be preferable to conventional intermittent bolus administration of beta-lactam antibiotics for serious Gram-negative infections. Severe melioidosis (Burkholderia pseudomallei infection) carries a mortality of $40 \%$ despite treatment with high dose ceftazidime. The aim of this study was to measure the pharmacokinetic and pharmacodynamic effects of continuous infusion of ceftazidime $v$ s intermittent bolus dosing in septicaemic melioidosis.

Methods Patients with suspected septicaemic melioidosis were randomised to receive ceftazidime $40 \mathrm{mg} \mathrm{kg}^{-1} 8$ hourly by bolus injection or $4 \mathrm{mg} \mathrm{kg}^{-1} \mathrm{~h}^{-1}$ by constant infusion following a $12 \mathrm{mg} \mathrm{kg}{ }^{-1}$ priming dose to perform estimation of pharmacokinetic and pharmacodynamic parameters.

Results Of the 34 patients studied $16(59 \%)$ died. Twenty patients had cultures positive for B. pseudomallei of whom $12(60 \%)$ died. The median $\mathrm{MIC}_{90}$ of $B$. pseudomallei was $2 \mathrm{mg}^{-1}$, giving a target concentration $C_{\mathrm{T}}$, of $8 \mathrm{mgl}^{-1}$. The median (range) estimated total apparent volume of distribution, systemic clearance and terminal elimination half-lives of ceftazidime were $0.468(0.241-0.573) 1 \mathrm{~kg}^{-1}, 0.058$ (0.005-0.159) $1 \mathrm{~kg}^{-1} \mathrm{~h}^{-1}$ and $7.74(1.95-44.71) \mathrm{h}$, respectively. Clearance of ceftazidime and creatinine clearance were correlated closely $(r=0.71 ; P<0.001)$ and there was no evidence of significant nonrenal clearance.

Conclusions Simulations based on these data and the ceftazidime sensitivity of the $B$. pseudomallei isolates indicated that administration by constant infusion would allow significant dose reduction and cost saving. With conventional $8 \mathrm{~h}$ intermittent dosing to patients with normal renal function, plasma ceftazidime concentrations could fall below the target concentration but this would be unlikely with a constant infusion. Correction for renal failure which is common in these patients is Clearance $=k$ creatinine clearance where $k=0.072$. Calculation of a loading dose gives median (range) values of loading dose, $D_{\mathrm{L}}$ of $3.7 \mathrm{mg} \mathrm{kg}^{-1}$ (1.9-4.6) and infusion rate $\mathrm{I}=0.46 \mathrm{mg} \mathrm{kg} \mathrm{h}^{-1}(0.04-1.3)$ (which equals $14.8 \mathrm{mg} \mathrm{kg}^{-1} \mathrm{day}^{-1}$ ). A nomogram for adjustment in renal failure is given.
\end{abstract}

Keywords: Burkholderia pseudomallei, ceftazidime, continuous infusion, melioidosis therapy, pharmacodynamics, pharmacokinetics

Correspondence: Professor N.J. White, Faculty of Tropical Medicine, Mahidol University, 420/6 Rajvithi Road, Bangkok 10400, Thailand. Tel.: 662-246-0832; Fax: 662-246-7795; E-mail: fnnjw@diamond.mahidol.ac.th

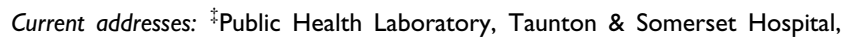
Taunton, United Kingdom. 'Wellcome Unit, Queen Elizabeth Hospital, Blantyre, Malawi.

\section{Introduction}

Recent appreciation of the differences in pharmacodynamic properties between different classes of antimicrobials has led to revised recommendations on dosing in 
severe infections. The aminoglycoside antibiotics have a rapid killing action against Gram-negative bacilli, which is dose-dependent (indicative of a 'flat' concentration effect relationship, i.e. the effect is directly proportional to the dose through the whole of the dose range) and is associated with a prolonged postantibiotic effect (PAE) [1]. In contrast toxicity to the kidney occurs well within the therapeutic range and appears to be related to the duration for which plasma concentrations exceed a toxic threshold. This allows once daily administration compared with traditional twice or thrice daily dosing with gentamicin [2]. In contrast the beta-lactam antibiotics have relatively slower kill-rates sometimes preceded by a lag-phase. They have a relatively steep concentration effect relationship such that concentrations above the minimum bactericidal concentration (MBC) at the site of the infection convey no additional cidal effect. With the exception of the carbapenems, beta-lactam antibiotics also have little or no PAE against Gram negative organisms. Bacterial killing by the beta-lactams depends on the duration for which the serum concentrations exceed the MBC [3, 4]. These data argue in favour of administering the beta-lactam antibiotics either by continuous intravenous infusion or in frequent bolus doses so that the blood concentrations do not fall below the MBC during the dosing interval.

Intravenous bolus dosing and constant infusion of ceftazidime have been studied in serious Gram negative infections in animals [5]. Bolus administration produced significantly higher peak concentrations in liver and lung as well as serum, whereas higher concentrations were found in the kidneys during constant infusion. An in vitro pharmacokinetic-pharmacodynamic model of ceftazidime killing of Pseudomonas aeruginosa has suggested that achievement of sustained concentrations of drug, four times the minimum inhibitory concentration (MIC), by continuous infusion was more efficacious than intermittent dosing [6]. This has also been confirmed in vivo in intensive care patients [7]. Further arguments for the theoretical benefits of continuous infusion of beta-lactams have been reviewed recently $[8,9]$.

Melioidosis is a severe infection caused by the Gramnegative bacillus, Burkholderia (Pseudomonas) pseudomallei. Septicaemia is the most common clinical presentation of melioidosis [10]. Despite prolonged courses of high dose, ceftazidime, the current drug of choice, mortality remains high at $40 \%[11,12]$. B. pseudomallei can often be cultured from blood for many days after beginning intravenous treatment with intermittent bolus doses of beta-lactam antibiotics. Although conventional in vitro $\mathrm{MIC} / \mathrm{MBC}$ assessment of ceftazidime indicates good activity against $B$. pseudomallei ( $\mathrm{MIC}_{90} 2 \mathrm{mg}^{-1}$ ) [13], it was not significantly cidal over a $24 \mathrm{~h}$ period in a time-kill kinetic study [14]. As administration of ceftazidime by continuous infusion is preferable theoretically in the treatment of septicaemic melioidosis, we have conducted a prospective study of the pharmacokinetics and in vivo bacterial killing rates (pharmacodynamics) of ceftazidime given either by continuous intravenous infusion or by conventional 8 hourly intravenous injections.

\section{Methods}

\section{Patients}

Patients or their relatives gave fully informed consent to inclusion in this study, which was approved by the Ethical and Scientific Review subcommittee of the Thai Ministry of Public Health. As in previous studies [11, 12] adults ( $>14$ years of age) admitted to the Department of Medicine, Sappasitprasong Hospital, Ubon Ratchatani, Thailand who were suspected clinically of having septicaemic melioidosis were included provided that they or their relatives gave fully informed consent to the study procedures. Pregnant women, patients who had already received effective antimicrobial therapy and those with known hypersensitivity to beta-lactam antibiotics were excluded.

Clinical and laboratory procedures were as described previously $[11,12]$. Patients were weighed and blood was taken for measurement of plasma electrolytes, glucose, lactate, renal and liver function tests and coagulation indices. Arterial blood gases and $\mathrm{pH}$ were measured if indicated clinically. Three standard blood cultures $(5 \mathrm{ml}$ of blood in $50 \mathrm{ml}$ brain-heart infusion broth (Tissue Culture Services, U.K.) and three pour-plate cultures $(1 \mathrm{ml}$ heparinized blood added to $19 \mathrm{ml}$ molten $\left(50^{\circ} \mathrm{C}\right)$ Columbia agar) for quantitative bacteriology [15] were taken immediately before administration of ceftazidime. Throat swabs, urine samples, pus from any wound or abscess, and sputum samples, were collected for culture on nonselective and selective media [16]. B. pseudomallei was identified as described previously [17].

\section{Treatment}

Patients were randomised to receive ceftazidime $120 \mathrm{mg}$ $\mathrm{kg}^{-1}$ day $^{-1}$ in normal saline; (Fortum ${ }^{\circledR}$, Glaxo, Greenford, UK) either by continuous infusion or intermittent bolus injection.

Group A: $40 \mathrm{mg} \mathrm{kg}^{-1}$ every 8 h, i.e. three times daily by intravenous intermittent bolus injection.

Group B: $12 \mathrm{mg} \mathrm{kg}^{-1}$ loading dose, followed by $4 \mathrm{mg}$ $\mathrm{kg}^{-1} \mathrm{~h}^{-1}$ by constant rate infusion.

For a typical $50 \mathrm{~kg}$ patient Group A received $6 \mathrm{~g}$ day $^{-1}$ and Group B $5.4 \mathrm{~g}$ on the first day and thereafter $4.8 \mathrm{~g}$ daily. Parenteral treatment was given for a minimum of 10 days. Maintenance oral treatment with amoxycillin/ clavulanic acid or the combination of cotrimoxazole, 
chloramphenicol and doxycycline was then given as part of studies reported elsewhere [18].

The dose of ceftazidime was reduced in renal failure after the first dose by adjusting for serum creatinine according to the standard prescription information [19]. Other supportive treatment was given as indicated clinically.

\section{Observations}

Vital signs were recorded every $4 \mathrm{~h}$ and a detailed clinical examination was performed daily. Patients who did not prove subsequently to have culture-confirmed melioidosis were withdrawn from the study and treated with appropriate antimicrobial therapy. Blood samples $(2 \mathrm{ml})$ for ceftazidime concentrations and pour plates for quantitative assessment of bacteraemia [15] were taken at the following times:

Group A (bolus): 0, $10 \mathrm{~min}, 30 \mathrm{~min}, 1 \mathrm{~h}, 2,3,4,6,8$, $8 \mathrm{~h} 10 \mathrm{~min}, 16,16 \mathrm{~h} 10 \mathrm{~min}, 24 \mathrm{~h}, 24 \mathrm{~h} 10 \mathrm{~min}$ and then daily peak and trough concentrations.

Group B (infusion): 0, $30 \mathrm{~min}, 1 \mathrm{~h}, 2,3,4,6,8,12,16$, $24 \mathrm{~h}$ and then 12 hourly.

Pour-plate blood cultures were repeated at 24 and $72 \mathrm{~h}$. Heparinized blood samples were centrifuged. Plasma was separated and stored at $-20^{\circ} \mathrm{C}$ for 1 month then $-70^{\circ} \mathrm{C}$ until analysis.

\section{Ceftazidime measurement}

All sampling was discontinued when blood culture/pour plate became negative after a minimum of $48 \mathrm{~h}$ incubation. Patients then continued with standard bolus ceftazidime or another antibiotic regime as appropriate. Plasma concentrations of ceftazidime were measured by h.p.l.c. as described previously with a level of detection of $0.1 \mathrm{mgl}^{-1}$ and a interassay coefficient of variation of $4 \%$ at concentrations of $0.5 \mathrm{mgl}^{-1}$ [20].

\section{Analysis}

The plasma concentration-time series were analysed using WinNonlin 1.1 (Statistical Consultants Inc., Kentucky, USA 1996) and pharmacokinetic models chosen on the basis of minimization of the Aikake Information Criterion (AIC). Simple one-compartment models provided the best fits to the plasma ceftazidime concentration-time data. Standard pharmacokinetic parameters were generated and the medians, maxima and minima of these derived parameters, total apparent volume of distribution $\left(V_{z}\right)$ and first order elimination rate constants $\left(K_{10}\right)$ were then used to model data to explore relationships with the measured MIC of the patients' own Burkholderia pseudomallei isolates [13]. Ceftazidime clearance was calculated from the formula $\mathrm{CL}=V_{\mathrm{z}} K_{10}$. Creatinine clearance was estimated by the method of Cockcroft \& Gault [21]. Although not as reliable as measuring creatinine clearance directly this formula has been validated in an Asian population [22].

Normally distributed continuous data was compared using Student's $t$-test. Data not conforming to a normal distribution were compared using the Mann-Whitney $U$ test and correlations were by the method of Spearman. Proportions were compared using the $\chi^{2}$ test with Yates' correction. Survival rates were plotted using the KaplanMeier method and compared using the log rank test. Linear regression was by the least squares method and a forward and backward stepwise multiple logistic regression model was used to examine the influence of pre-existing patient variables listed in Table 1 upon the derived pharmacokinetic parameters. All analyses were performed using the statistical computing package SPSS for Windows, version 6.1 (SPSS Inc., Chicago, U.S.A.).

\section{Results}

Between June and October 199334 patients were entered into the study. Data from 21 were suitable for pharmacokinetic analysis. Of these 21, five patients had culture proven melioidosis but were not septicaemic, 15 patients had septicaemic melioidosis of whom seven had positive pour-plate cultures (i.e. $>0.33 \mathrm{cfu} \mathrm{ml}^{-1}$ blood), and six did not prove to have melioidosis. Two of the six 'nonmelioidosis' patients had other Gram-negative septicaemia (one Escherichia coli and one Klebsiella pneumoniae). The other four were blood culture negative, two patients were HIV antibody positive and three patients had culture negative pneumonias. The demographic details of the 15 patients with melioidosis were similar to those with other diagnoses (Table 1). The overall mortality was 59\%. Twelve (60\%) of the patients with melioidosis and 4 (57\%) of the nonmelioidosis patients died. The mortality in the melioidosis pour-plate positive group $\left(>1 \mathrm{cfu} \mathrm{ml}^{-1}\right)$ was $82 \%(P<0.001)$. There was no difference between the bolus and infusion groups by survival analysis (log rank $P=0.89$ ). All of the 24 isolates of $B$. pseudomallei were sensitive to ceftazidime in vitro with a median (range) MIC of $2 \mathrm{mg} \mathrm{l}^{-1}(0.3-4)$, , i.e. a target concentration of $8 \mathrm{mg} \mathrm{l}^{-1}$ would be required to achieve the median $4 \times$ MIC.

\section{Pharmacokinetics}

Eighteen patients received ceftazidime by constant rate infusion and 14 by intermittent bolus injections. However, in only 10 of the infusion group and 11 of the bolus group could the pharmacokinetic parameters be derived adequately. This was because plasma drug-concentration 
Table 1 Clinical features on admission (median/range).

\begin{tabular}{llll}
\hline & Bolus $(\mathrm{n}=11)$ & Infusion $(\mathrm{n}=10)$ & Excluded $*(\mathrm{n}=13)$ \\
\hline Age (years) & $43(27-73)$ & $48(29-58)$ & $54(18-67)$ \\
Sex F:M & $7: 4$ & $1: 9$ & $10: 3$ \\
Weight $(\mathrm{kg})$ & $50(45-65)$ & $48(40-64)$ & $50(35-75)$ \\
Blood culture positive & 5 & 3 & 6 \\
Pour plate positive & 7 & 4 & 9 \\
Blood culture negative & 0 & 4 & 1 \\
Not-melioidosis & 4 & 2 & 3 \\
Deaths & $9(82 \%)$ & $3(30 \%)$ & $11(85 \%)$ \\
Time to death $(\mathrm{h})$ & $60(8-240)$ & $34(20-624)$ & $10(1-624)$ \\
Serum creatinine $\left(\mathrm{mg} \mathrm{dl}{ }^{-1}\right)$ & $2.8(0.8-10.4)$ & $1.55(0.9-13)$ & $3.4(1-7.2)$ \\
(Normal range: $\left.0.8-1.7 \mathrm{mg} \mathrm{dl}^{-1}\right)$ & $23(8-94)$ & $38(5-69)$ & $21(8-50)$ \\
Estimated creatinine clearance $\left(\mathrm{ml} \mathrm{min}{ }^{-1}\right)$ & $21(9-27)$ & $15(3-23)$ & $12(3-24)$ \\
APACHE II score & $39.8(37.5-41)$ & $40(36.5-40.5)$ & $40.5(36.9-39.8)$ \\
Temperature $\left({ }^{\circ} \mathrm{C}\right)$ & $8(4-30)$ & $14(5-130)$ & $10(3-180)$ \\
Duration of previous symptoms (days) & & \\
\hline
\end{tabular}

$\star$ Eight patients received an infusion and five patients boluses of ceftazidime, exclusion as detailed in methods.

profiles fluctuated considerably, often within dosing intervals, in patients who died within $48 \mathrm{~h}$ and derived pharmacokinetic parameters could not be estimated reliably. There was no significant difference in peak and trough plasma ceftazidime concentrations at $8 \mathrm{~h}$ between those patients who survived (peak $182(130-252) \mathrm{mg}^{-1}$ trough $\left.44(2-126) \mathrm{mg} \mathrm{l}^{-1}\right)$ and those who died in the bolus group (peak 187 (72-552) $\mathrm{mg}^{-1}$ trough 61 (2-343) $\left.\mathrm{mg}^{-1}\right)$. Similarly there was no significant difference for those given ceftazidime by infusion. (survived 35 (19-43) $\mathrm{mg} \mathrm{l}^{-1}$; died 116 (49-136) $\mathrm{mg} \mathrm{l}^{-1}$. All of the melioidosis patients in both groups had ceftazidime concentrations above the target concentration $C_{\mathrm{T}}$ throughout the study. The higher concentrations in the fatal cases reflect the greater degree of renal impairment. Two patients without melioidosis had trough levels below the $C_{\mathrm{T}}$.

Overall in those patients who received bolus administration and whose plasma drug concentration-time data could be analysed, median peak plasma ceftazidime $\left(C_{\max }\right)$ was $194 \mathrm{mg} \mathrm{l}^{-1}$, and ranged between 553 and $147 \mathrm{mg} \mathrm{l}^{-1}$ at $8.17 \mathrm{~h}$. The median trough (pre dose) value at $8 \mathrm{~h}$ was $48 \mathrm{mg} \mathrm{l}^{-1}$ ranging between 1.8 and $344 \mathrm{mg} \mathrm{l}^{-1}$. For the infusion recipients plasma ceftazidime concentrations ranged between 7 and $212 \mathrm{mg}^{-1}$. At $30 \mathrm{~min}$ after starting the study the ceftazidime concentrations in the infusion group patients were significantly lower than the bolus concentrations $(P=0.006$ for culture positive and $P=0.05$ for culture negative patients) however, by $8 \mathrm{~h}$ there was no significant difference. In those patients in whom pharmacokinetic parameters could be estimated reliably there were no significant differences for volume of distribution, systemic clearance, or elimination rate constant when comparing administration methods (bolus $v s$ infusion). There was also no significant difference for the values between those patients who had or did not have culture proven melioidosis (Table 2). There was a linear relationship between estimated creatinine clearance and ceftazidime clearance $(r=0.71)$ (Figure 1$)$. From the fitted linear regression model the y-intercept of the graph of ceftazidime clearance $v$ s creatinine clearance was not significantly greater than zero (intercept mean (95\% CI) $\quad 0.014 \quad(-2.318-2.345) \quad P=0.99 ;$ slope 0.072 (0.018-0.126) $P=0.014)$ providing no evidence for nonrenal clearance of ceftazidime. In a forward stepwise linear regression model with the admission variables in Table 1 as the independent variables and ceftazidime clearance as the dependent variable, the estimated creatinine clearance accounted for $53 \%$ of the variation in ceftazidime clearance in these patients. No other factors contributed significantly. Using the median, maximum and minimum values of the derived parameters the simulated models of infusion and bolus administration were compared (Figure 2). The two patients who had trough concentrations below the median $\mathrm{MIC}_{90}$ of $B$. pseudomallei did not have culture proven melioidosis. The predicted range of plasma concentrations ceftazidime for the intermittent bolus injection regimen fell just below $8 \mathrm{mg}^{-1}(4 \times \mathrm{MIC})$ before dosing. Reducing the dose interval to 6 hourly did not improve this (data not shown).

\section{Pharmacodynamics}

Fourteen patients with melioidosis and bacteraemia $>1 \mathrm{cfu} \mathrm{ml} \mathrm{m}^{-1}$ (i.e. who were pour plate positive for $B$. pseudomallei) were studied. Four of these patients did not have a simultaneous pharmacokinetic study. Six patients received bolus injections and eight received infusions. The 
Table 2 Pharmacokinetic parameters (median, range) of ceftazidine following bolus injection or constant infusion.

\begin{tabular}{llll}
\hline & Overall $(\mathrm{n}=21)$ & Bolus $(\mathrm{n}=11)$ & Infusion (n=10) \\
\hline$V_{\mathrm{z}}\left(1 \mathrm{~kg}^{-1}\right)$ & $0.468(0.241-0.573)$ & $0.450(0.254-0.573)$ & $0.486(0.241-0.569)$ \\
$K_{10}\left(\mathrm{~h}^{-1}\right)$ & $7.53(0.93-21.3)$ & $3.48(0.93-21.3)$ & $11.58(7.2-15.72)$ \\
$\mathrm{AUC}\left(\mathrm{mg} \mathrm{l}^{-1} \mathrm{~h}\right)$ & & $1496(251-8834)$ & $3.59(2.65-5.78)$ \\
$t_{1 / 2, \mathrm{z}}(\mathrm{h})$ & $7.74(1.95-44.71)$ & $11.89(1.95-44.71)$ & \\
$C_{\mathrm{ss}}\left(\mathrm{mg} \mathrm{l}^{-1}\right)$ & & $75.5(34-89.5)$ & $89.6(69.8-157.5)$ \\
$C_{\max }\left(\mathrm{mg} \mathrm{l}^{-1}\right)$ & $0.058(0.005-0.159)$ & $0.027 \star(0.005-0.159)$ & $0.089 \star(0.038-0.125)$ \\
$\mathrm{CL}\left(1 \mathrm{~kg}^{-1} \mathrm{~h}^{-1}\right)$ & & & \\
\hline
\end{tabular}

$\star P<0.05$ Mann-Whitney $U$-test comparing bolus $v$ s infusion groups.

original objective of the study to compare bacterial clearance rates between the two regimens could not be fulfilled because the overall mortality was so high in pour plate positive patients; only one patient survived and only three became pour plate negative before death. The median (range) bacteraemia of B. pseudomallei at time of entry to the study in this poor prognosis subgroup was 75 (1-2045) $\mathrm{cfu} \mathrm{ml}^{-1}$ and the median (range) time to death was $25(2-480) \mathrm{h}$. There were no significant differences between the two treatment groups in terms of entry criteria although the continuous infusion group had slightly lower APACHE scores and also lower predicted mortality. The fractional fall in B. pseudomallei count $\left(\mathrm{cfu} \mathrm{ml} \mathrm{m}^{-1}\right.$ ) at $8 \mathrm{~h}$ (i.e. before the second dose of ceftazidime) as a percentage of the initial count was significantly different between the groups. The bolus group increased slightly with a median (range) of $0.5 \%$ (19.5\% increase to $4 \%$ decrease) whereas all of the infusion group patients' counts fell with a median of $7 \%$ range (0-13\% decrease) $P=0.025$ (Figure 3).

\section{Discussion}

Melioidosis is a major cause of community-acquired septicaemia in south-east Asia. In the province of Ubon Ratchatani in north-eastern Thailand the annual incidence of melioidosis is 4.4 per 100000 , and septicaemic melioidosis accounts for $19 \%$ of all community-acquired septicaemias admitted to hospital [10, 23]. The infection is thus a major cause of death in this region. The use of ceftazidime (given in intermittent high-dose boluses) has reduced the mortality of melioidosis from $\approx 80 \%$ to $40 \%$ [11]. However, the mortality in patients with quantifiable bacteraemias (i.e. $>1 \mathrm{cfu} \mathrm{ml}^{-1}$ ) remains very high [15] despite prompt and appropriate treatment. Ceftazidime treatment of melioidosis is very expensive (approximately $\$ 100$ a day or over 20 times the minimum daily wage in this area) and must be given for at least 10 days, imposing a considerable financial burden on the local health services. The objective of this study was to devise the optimum cost-effective intravenous regimen for ceftazidime admin- istration in severe melioidosis on the basis of pharmacokinetic and pharmacodynamic measures.

In healthy volunteers the mean total apparent volume of distribution of ceftazidime is between 15 and 201 (i.e. $0.2-0.31 \mathrm{~kg}^{-1}$ ) [24], and with normal renal function, the elimination half-life is usually between 1 and $3 \mathrm{~h}$. Women have a slightly smaller total apparent volume of distribution for ceftazidime than men [25], and systemic clearance is reduced with age, partly as a result of decreased renal function [26]. In this study of severe melioidosis, as in other studies, the predominant route of ceftazidime clearance found to be renal elimination accounting for between $52 \%$ and $96 \%$ of total plasma clearance $[27,28]$. Ceftazidime is a widely used antibiotic particularly for the treatment of Pseudomonas infections in patients with cystic fibrosis [29]. In this group of patients both volume of distribution and renal clearance are increased. This has been attributed to fever-induced increases in renal blood flow. However, in more severely ill patients who do not have cystic fibrosis renal blood flow [30], as a fraction of cardiac index, is not increased.

Previous studies of ceftazidime pharmacokinetics in severely ill patients show a wide variation in estimated clearance and volume of distribution [31-33] although in

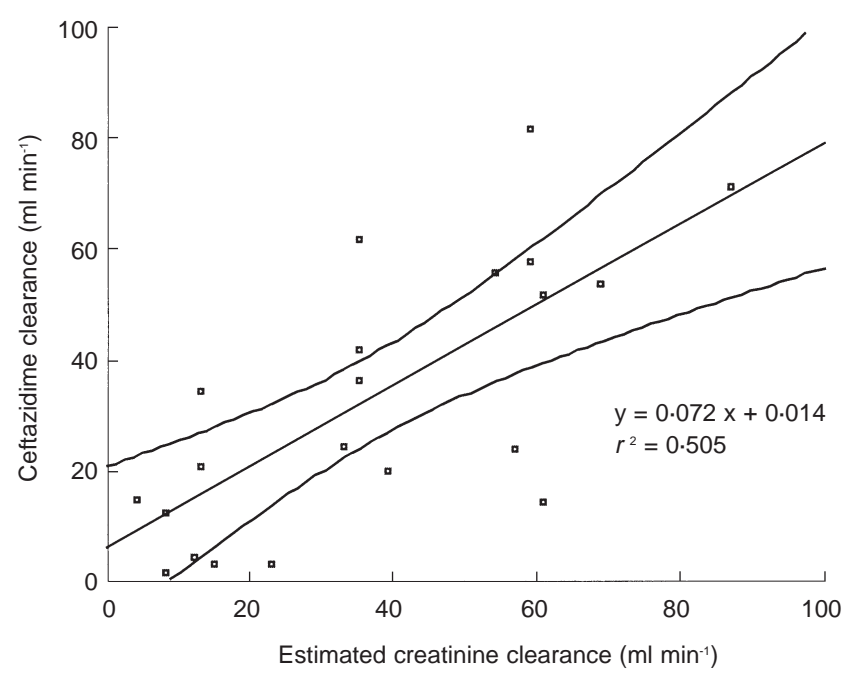

Figure 1 Ceftazidime clearance $v s$ estimated creatinine clearance. 


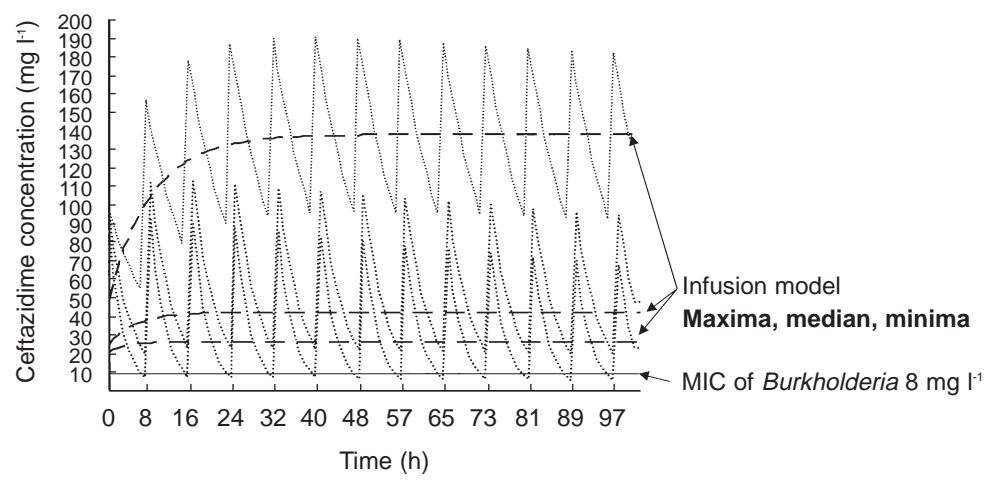

Figure 2 Models derived using derived pharmacokinetic parameters. (Maxima, minima and median values from bolus (dotted lines) and infusion (dashed lines) groups in the simulation modules in Winnonlin. Also shown is minimum inhibitory concentration (MIC). every study, including the present one, renal function remains the major determinant of ceftazidime clearance. The pharmacokinetic properties of ceftazidime in Thai patients with septicaemic melioidosis were similar to those reported previously in patients with other causes of shock and renal failure. Total apparent volume of distribution was larger than in healthy subjects, and systemic clearance was reduced - largely as a result of renal impairment which is very common in septicaemic melioidosis. The difference in clearance between the bolus and the infusion groups probably results from the slight difference in creatinine clearance at randomization. The ratios of estimated ceftazidime to creatinine clearance were similar. In a multiple regression model of the factors influencing ceftazidime clearance, estimated creatinine clearance contributed most to the variation seen in this patient group. The APACHE scoring system does take into account creatinine clearance but also other measures of severity of illness [34]. In this series the APACHE score consistently underestimated the risk of death of these patients. This may be due to differences in the availability of intensive support available in this area. Approximately $1 \%$ of ceftazidime clearance is through biliary excretion. Previous studies in chronic liver failure and in cirrhosis have shown changes in volume of distribution resulting in shortened elimination half-times with no overall change in total body clearance $[35,36]$. There was no evidence for significant nonrenal clearance in this study [37]. Although the patients in the study with severe melioidosis were hypoalbuminaemic, this is unlikely to have affected the disposition of ceftazidime as plasma protein binding is low $(\approx 17 \%)[38,39]$.

There has been debate recently about optimization of ceftazidime delivery in critically ill septic patients. It is generally considered that continuous infusion is superior to intermittent bolus dosage in terms of a more favourable time concentration profile. Young et al. [40] found trough concentrations of ceftazidime below the median MIC for $P$. aeruginosa given intermittent bolus dosing in over half of 7 critically ill patients studied. All had normal renal function. In our study only 2 patient's, neither of whom had melioidosis, had plasma ceftazidime concentration below the MIC for B. psendomallei. The renal failure associated with melioidosis 'protects' against low trough concentrations. Benko et al. [41] also found continuous infusion always maintained serum concentrations over the MIC whereas with the bolus administration concentrations fell below MIC for $8 \%$ of the time. The present study had similar findings. Modelling these data it can be predicted that large bolus dosing will give plasma

Table 3 Nomogram for reduction of ceftazidime dose in renal failure.

\begin{tabular}{|c|c|c|c|}
\hline $\begin{array}{l}\text { Estimated creatinine } \\
\text { clearance }\left(\mathrm{ml} \mathrm{min}^{-1}\right)\end{array}$ & $\begin{array}{l}\text { Bolus dosage } \\
\text { (total in } 24 \mathrm{~h} \text { ) }\end{array}$ & $\begin{array}{l}\text { Loading dose } \\
\text { for infusion } \\
\left(m g \mathrm{~kg}^{-1}\right)\end{array}$ & $\begin{array}{c}\text { Infusion rate } \\
\left(m g \mathrm{~kg}^{-1} \mathrm{~h}^{-1}\right) \\
(\text { total over } 24 \mathrm{~h})\end{array}$ \\
\hline 50 & $\begin{array}{c}40 \mathrm{mg} \mathrm{kg}^{-1} \\
\text { every } 8 \mathrm{~h} \mathrm{(120)}\end{array}$ & 4 & $3.6(90.4)$ \\
\hline $31-50$ & $\begin{array}{l}20 \mathrm{mg} \mathrm{kg}^{-1} \\
\text { every } 12 \mathrm{~h}(80)\end{array}$ & 4 & $1.8(47.2)$ \\
\hline $15-30$ & $\begin{array}{c}20 \mathrm{mg} \mathrm{kg}^{-1} \\
\text { every } 24 \mathrm{~h}(20)\end{array}$ & 4 & $1.1(30.4)$ \\
\hline$<15$ & $\begin{array}{l}10 \mathrm{mg} \mathrm{kg}^{-1} \\
\text { every } 24 \mathrm{~h}(10)\end{array}$ & 4 & $0.8(23.2)$ \\
\hline
\end{tabular}

Bolus dosage (loading dose in $\mathrm{mg} \mathrm{kg}^{-1}$ and dose interval, total dose $\left(\mathrm{mg} \mathrm{kg}^{-1}\right)$ over $24 \mathrm{~h}$ in brackets). Infusion dosage (loading dose in $\mathrm{mg} \mathrm{kg}^{-1}$ and infusion rate, total dose $\left(\mathrm{mg} \mathrm{kg}^{-1}\right)$ over $24 \mathrm{~h}$ in brackets). 
concentrations below the median MIC for Burkholderia pseudomallei for of a small fraction the dosing interval when renal function is normal (Figure 2). It remains unclear whether would have an adverse effect on outcome, since although the original objective of these studies was to relate pharmacokinetic parameters to pharmacodynamic measures, this could not be achieved because of the high mortality in patients with quantifiable bacteraemias. Previous studies with $P$. aeruginosa $[6,42]$ have suggested that sustained achievement of plasma concentrations at or above four times the MIC for the infecting organism provides optimum therapeutic effect, but there are no comparable data for B. pseudomallei - a bacterium which is genetically much closer to $B$. cepacia than to $P$. aeruginosa. B. pseudomallei is intrinsically resistant to many antibiotics and even relatively resistant to those antibiotics that do have in vitro activity.

Since creatinine clearance is the major determinant of ceftazidime clearance dose reduction is recommended when renal function is impaired. Although the therapeutic ratio is very wide neurotoxicity (seizures) has been reported in patients with renal failure [43]. Calculation of the dose reduction for a continuous infusion necessary in renal impairment is relatively simple (see Appendix). At very low values of renal clearance the nonrenal component may become significant.

Perhaps the main advantage of giving ceftazidime by a constant infusion, provided that equipment such as infusion pumps or infusion chambers are available, is a significant cost saving. Simple infusion devices have already been used successfully to deliver continuous infusions of ceftazidime in the United States [44] and in Northern Australia where melioidosis is also endemic. (B. Currie, personal communication). The average saving in a 14 day course of intravenous treatment of melioidosis in patients with unimpaired renal function would be $16.2 \mathrm{~g}$ of ceftazidime or $19 \%$ of the overall dose. This would amount to a cost saving per patient of 8800 Thai baht or $\$ 220$ at current prices while still maintaining blood antibiotic concentrations well above four times the MIC. There would also be savings in nursing staff time and costs for preparation and administration of a single infusion rather than three doses of drug. Drug administration by a single simple intravenous infusion set such as that used in Australia would not add to the costs since there would only be one used per day as opposed to three.

We thank the medical and nursing staff of the Department of Medicine, Sappasitprasong Hospital for their help in performing this study and Mr S. Langla for technical assistance. This study was part of the Wellcome-Mahidol University, Oxford Tropical Medicine Research Programme, funded by the Wellcome Trust for Great Britain.

\section{Appendix}

Calculation of a loading dose, infusion rate and dose reductions in renal failure

Calculation of the loading dose $\left(\mathrm{mg} \mathrm{kg}^{-1}\right)$ is from the equation: $D_{\mathrm{L}}=C_{\mathrm{T}} \star V_{\mathrm{z}, \mathrm{ss}}$ (where $C_{\mathrm{T}}$ is the target concentration $\left(\mathrm{mg} \mathrm{l}^{-1}\right)$ and $V_{\mathrm{z}, \mathrm{ss}}$ the volume of distribution at steady state $\left.\left(\mathrm{kg}^{-1}\right)\right)$. Calculation of the infusion rate is: $\mathrm{I}=C_{\mathrm{T}} \star \mathrm{CL}$ (where $\mathrm{CL}$ is ceftazidime clearance which equals $0072 \star$ estimated creatinine clearance $+0.014)$. This gives median (range) values of $D_{\mathrm{L}}=8 \star$ $0.468=3.7 \mathrm{mg} \mathrm{kg}^{-1}(1.9-4.6)$ and $\mathrm{I}=8$ * $\left(0.072 \mathrm{CL}_{\mathrm{Cr}}\right.$ $+0.014)=3.6 \mathrm{mg} \mathrm{kg}^{-1} \mathrm{~h}^{-1}(0.4-13)$ for a creatinine clearance of $100 \mathrm{ml} \mathrm{min}^{-1}$. This equals a total infusion dose of 90 as compared with $120 \mathrm{mg} \mathrm{kg}^{-1}$ day $^{-1}$. This is shown as a nomogram in Table 3.

\section{References}

1 Mattie H, Craig WA, Pechere JC. Determinants of efficacy and toxicity of aminoglycosides. J Antimicrob Chemother 1989; 24: 281-293.

2 Gilbert DN. Once daily aminoglycoside therapy. Antimicrob Agents Chemother 1991; 35: 339-405.

3 Vogelman B, Gudmundsson S, Leggett J. Correlation of antimicrobial pharmacokinetic parameters with therapeutic efficacy in an animal model. J Infect Dis 1988; 158: 831-847.

4 Drusano G. Role of pharmacokinetics in the outcome of infections. Antimicrob Agents Chemother 1988; 32: 289-297.

5 Miglioli P, Xerri L, Palatini P. Influence of the mode of administration on the penetration of ceftazidime into tissues and pleural exudate of rats. Pharmacol 1991; 43: 242-246.

6 Mouton J, Hollander JD. Killing of Pseudomonas aeruginosa during continuous and intermittent infusion of ceftazidime in an in vitro pharmacokinetic model. Antimicrob Agents Chemother 1994; 38: 931-936.

7 Lipman J, Gomersall CD, Gin T, Joynt GM, Young RJ. Continuous infusion ceftazidime in intensive care: a randomized controlled trial J Antimicrob Chemother 1999; 43: 309-311.

8 Turnidge JD. The pharmacodynamics of beta-lactams. Clin Infect Dis 1998; 27: 10-22.

9 Vondracek TG. Beta-lactam antibiotics: is continuous infusion the preferred method of administration? Ann Pharmacother 1995; 29: 415-424.

10 Chaowagul W, White NJ, Dance DAB, et al. Melioidosis: a major cause of community-acquired septicaemia in North-Eastern Thailand. J Infect Dis 1989; 129: 890-899.

11 White NJ, Dance DAB, Chaowagul W, et al. Halving of mortality of severe melioidosis by ceftazidime. Lancet 1989; ii: 697-701.

12 Suputtamongkol Y, Rajchanuvong A, Chaowagul W, et al. Ceftazidime vs Amoxicillin/clavulanate in treatment of severe melioidosis. Clin Infect Dis 1994; 19: 846-853.

13 Dance DAB, Wuthiekanun V, Chaowagul W, White NJ. The antimicrobial susceptibility of Pseudomonas pseudomallei. 
Emergence of resistance in vitro and during treatment. J Antimicrob Chemother 1989; 24: 295-309.

14 Smith MD, Wuthiekanun V, Walsh AL, White NJ. Susceptibility of Pseudomonas pseudomallei to some newer beta-lactam antibiotic combinations using time-kill studies. J Antimicrob Chemother 1994; 33: 145-149.

15 Walsh AL, Smith MD, Wuthiekanun V, et al. Prognostic significance of quantitative bacteraemia in septicamic melioidosis. Clin Infect Dis 1995; 21: 1498-1500.

16 Wuthiekanun V, Dance DAB, Wattanagoon Y, et al. The use of selective media for the isolation of Pseudomonas pseudomallei in clinical practice. J Med Microbiol 1990; 33: 121-126.

17 Dance DAB, Wuthiekanun V, Naigowit P, et al. Identification of Pseudomonas pseudomallei in clinical practice: use of simple screening tests and API 2ONE. J Clin Pathol 1989; 42: 645-648.

18 Rajchanuvong A, Chaowagul W, Suputtamongkol Y, et al. A prospective comparison of co-amoxiclav and the combination of chloramphenicol, doxycycline, and co-trimoxazole for the oral maintenance Treatment Melioidosis. Trans $R$ Soc Trop Med Hyg 1995; 89: 546-549.

19 van Dalen R, Vree TB, Baars AM, et al. Dosage adjustment for ceftazidime in patients with impaired renal function. Eur J Clin Pharmacol 1986; 30: 597-605.

20 Myers C, Blumer J. Determination of ceftazidime in biological fluids by using high-pressure liquid chromatography. Antimicrob Agents Chemother 1983; 24: 343-346.

21 Cockcroft DW, Gault MW. Prediction of creatinine clearance from serum creatinine. Nephron 1976; 16: 31-42.

22 Robertshaw M, Lai KN, Swaminathan R. Prediction of creatinine clearance from plasma creatinine: comparison of five formulae. Br J Clin Pharmacol 1989; 28: 275-280.

23 Suputtamongkol Y, Hall AJ, Dance DAB, et al. The Epidemiol Melioidosis Ubon Ratchatani, North East Thailand. Int J Epidemiol 1994; 23: 1082-1090.

24 Richards D, Brogden R. Ceftazidime: A review of its antibacterial activity, phamacokinetic properties and therapeutic use. Drugs 1985; 29: 105-161.

25 Sommers DK, Walters L, Van Wyk M, et al. Pharmacokinetics of ceftazidime in male and female volunteers. Antimicrob Agents Chemother 1983; 23: 892-896.

26 Ljungberg B, Ehle-Nilsson I. Advancing age and acute infection influence the kinetics of ceftazidime. Scand J Infect Dis 1989; 21: 327-332.

27 Leroy A, Leguy F, Borsa F, et al. Pharmacokinetics of ceftazidime in normal and uraemic subjects. Antimicrob Agents Chemother 1984; 25: 638-642.

28 Lin M, Wang L, Huang J. Single and multiple dose pharmacokinetics of ceftazidime in infected patients with varying degrees of renal function. J Clin Pharmacol 1989; 29: 331-337.
29 Vinks AA, Brimicombe RW, Heijerman HG, Bakker W. Continuous infusion of ceftazidime in cystic fibrosis patients during home treatment: clinical outcome, microbiology and pharmacokinetics. J Antimocrob Chemother 1997; 40: 125-133.

30 Ganzinger U, Kleinberger G, Lenz K, et al. Pharmacokinetics of ceftazidime and netilimicin in patients with sepsis. Int J Pharmacol Ther Toxicol 1987; 25: 354-362.

31 Rondanelli R, Dionigi RV, Regazzi MB, et al. Ceftazidime in the treatment of Pseudomonas infections in intensive-care patients. Int J Clin Pharmacol Ther Toxicol 1986; 24: 457-459.

32 van-Dalen R, Vree T. Pharmacokinetics of antibiotics in critically ill patients. Intensive Care Med 1990; 16: S235-S238.

33 de Kinowski JM, la Coussaye JE, Bressolle F, et al. Multiple dose pharmacokinetics of amikacin and ceftazidime in critically ill patients with septic multiple-organ failure during intermittent hemofiltration. Antimicrob Agents Chemother 1993; 37: 464-473.

34 Prediction by APACHE Score Lancet 1986; ii: 286-287.

35 el Touny M, el Guinaidy MA, Abd el Barry M, et al. Pharmacokinetics of ceftazidime in patients with liver cirrhois and ascites. Antimicrob Agents Chemother 1991; 28: 95-100.

36 Pasko MT, Beam TR, Spooner JA, et al. Safety and pharmacokinetics of ceftazidime in patients with chronic hepatic dysfunction. J Antimicrob Chemother 1985; 15: 365-374.

37 Rowland M, Tozer T. Clinical pharmacokinetics: Concepts and applications, 1st edn. Philadelphia, London: Lea \& Febiger 1989.

38 Van-der-Auwera P, Klastersky J. Study of the influence of protein binding on serum bactericidal titres and killing rates in volunteers receiving ceftazidime, ceftotaxime and ceftriaxone. J Hospital Infection 1990; 15: 23-24.

39 Lam YW, Duroux MH, Gambertoglio JG, et al. Effect of protein binding on serum bactericidal activities of ceftazidime and cefoperazone in healthy volunteers. Antimicrob Agents Chemother 1988; 32: 298-302.

40 Young RJ, Lipman J, Gin T, et al. Intermittent bolus dosing of ceftazidime in critically ill patients. J Antimicrob Chemother 1997; 40: 269-273.

41 Benko AS, Cappelletty DM, Kruse JA, Rybak MJ. Continuous infusion versus intermittent administration of ceftazidime in critically ill patients with suspected Gram-negative infections. Antimicrob Agents Chemother 1996; 40: 691-695.

42 Manduru M, Mihm LB, White RL, et al. In vitro pharmacodynamics of ceftazidime against Pseudomonas aeruginosa isolates from cystic fibrosis patients. Antimicrob Agents Chemother 1997; 41: 2053-2056.

43 Gentry L. Antimicrobial activity, pharmacokinetics, therapeutic indications and adverse reactions of ceftazidime. Pharmacother 1985; 5: 254-267.

44 Couldry R, Sanborn M, Strayer AH. Continuous infusion of ceftazidime with an elastomeric infusion device $A m J$ Health Syst Pharm 1998; 55: 145-149. 